Journal of Science $\quad$ Gazi University

\title{
Exponentiated Weibull Distribution for Modeling the Vehicle Headway Data based on Ranked Set Sampling
}

\author{
Busra SEVINC',*(i), Selma GURLER ${ }^{2}$ (i) , Melek ESEMEN ${ }^{1}$ \\ ${ }^{I}$ Dokuz Eylul University, The Graduate School of Natural and Applied Sciences, Tinaztepe Campus, 35160 Buca, İzir, Turkey \\ ${ }^{2}$ Dokuz Eylul University, Department of Statistics, Faculty of Science, Tinaztepe Campus, 35160, Buca, Izmir, Turkey
}

\section{Highlights}

- Estimating the parameters of Exponentiated Weibull based on RSS.

- Modeling vehicle headway data using Exponentiated Weibull.

- Comparison of the performances of SRS and RSS methods.

\section{Article Info \\ Received: $29 / 01 / 2020$ \\ Accepted: $25 / 05 / 2020$ \\ Keywords \\ Exponentiated Weibull Ranked set sampling \\ Parameter estimation \\ Maximum likelihood \\ Headway modeling}

\begin{abstract}
Modeling the vehicle headway data is fundamental for intelligent transportation applications in traffic engineering. It is useful for the traffic signal optimization and flow modelling. Exponentiated Weibull (EW) is one of the best flexible model for characterizing uncertainty in various fields of data. In this study, we revisit EW distribution and propose to use of ranked set sampling as a useful sampling method for estimating the unknown parameters. We deal with the performance of ranked set sampling and simple random sampling methods by a simulation study in R-software in terms of mean squared errors. We estimate the parameters of EW distribution using the maximum likelihood method under the assumption that all parameters are unknown. We illustrate the flexibility and the usefulness of EW distribution by analysing generated data from a real application study in transportation field.
\end{abstract}

\section{INTRODUCTION}

Mudholkar and Srivastava [1] introduced the exponentiated Weibull (EW) distribution as a generalization of the Weibull distribution. EW distribution has a second shape parameter, and it is commonly used in modeling of data in various fields, such as reliability, finance, medicine and environmental studies. The detailed information can be found in [1-3] and additional results can be found in [4,5] for modelling with EW distribution.

The probability density function (pdf) and cumulative distribution function (cdf) of the EW family are given, respectively, by

$$
\begin{aligned}
& g(y ; \alpha, \beta, \lambda)=\alpha \beta \lambda^{\beta} y^{\beta-1} e^{-(\lambda y)^{\beta}}\left(1-e^{-(\lambda y)^{\beta}}\right)^{\alpha-1}, \\
& G(y ; \alpha, \beta, \lambda)=\left(1-e^{-(\lambda y)^{\beta}}\right)^{\alpha}, 0<y<\infty
\end{aligned}
$$

where $\lambda>0$ is the scale parameter, and, $\alpha>0$ and $\beta>0$ are referred to as the shape parameters [1]. The corresponding hazard function is

$r(y ; \alpha, \beta, \lambda)=\frac{\alpha \beta \lambda^{\beta} y^{\beta-1} e^{-(\lambda y)^{\beta}}\left(1-e^{-(\lambda y)^{\beta}}\right)^{\alpha-1}}{\left(1-e^{-(\lambda y)^{\beta}}\right)^{\alpha}}$. 
The hazard function has different shapes depending on parameter values, such as monotone increasing ( $\beta \geq$ $1, \alpha \beta \geq 1)$, monotone decreasing $(\beta \leq 1, \alpha \beta \leq 1)$, bath-tube shaped $(\beta>1, \alpha \beta<1)$ or unimodal $(\beta<$ $1, \alpha \beta>1$ ) (see, [6]). Figures 1 and 2 illustrate the shapes of the EW with different values of $\alpha, \beta$, and $\lambda$ for pdf and the hazard function, respectively. If $\alpha$ is equal to 1 , the distribution is said to be Weibull distribution, if $\beta$ is equal to 1 , it reduces to the exponentiated exponential model. If $\alpha$ and $\beta$ are both 1 , the distribution has a constant hazard function, that is exponential. For more results and references, one can see [7-12]. Also, comprehensive review about EW and other modified Weibull distributions can be found in $[13,14]$.

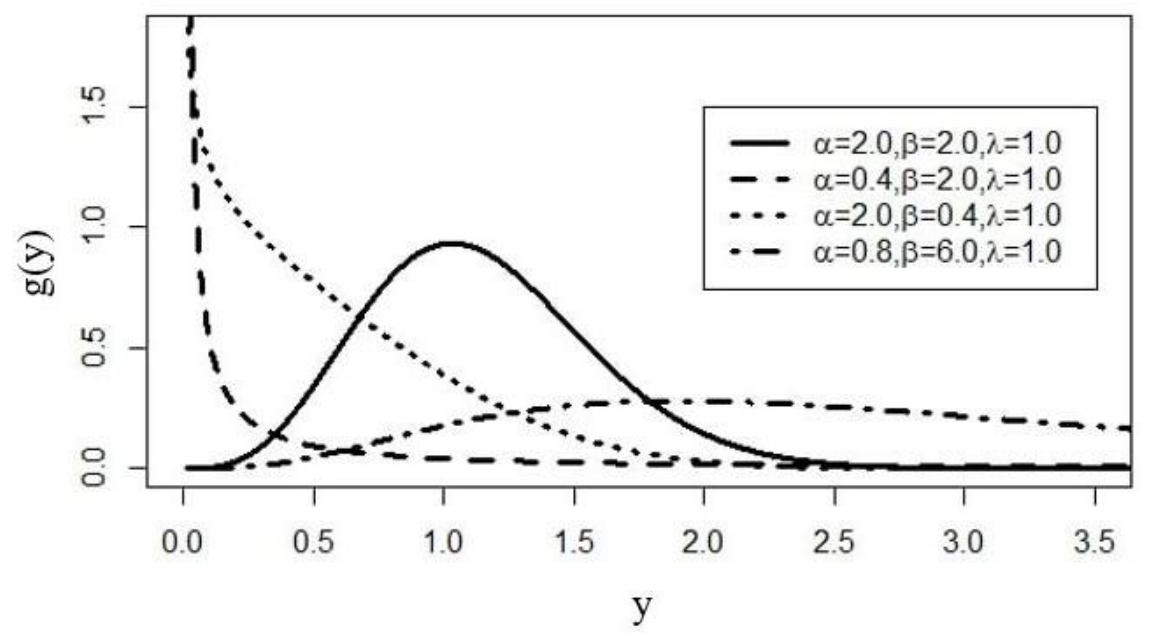

Figure 1. Pdf of EW for different values of parameters

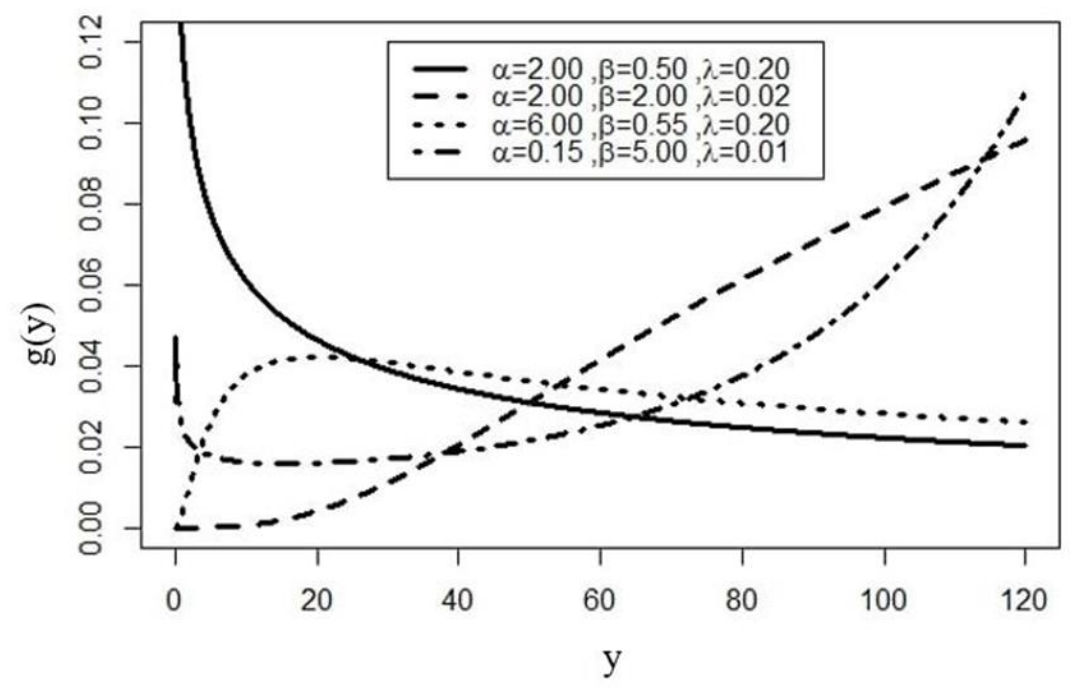

Figure 2. Hazard function of EW for different values of parameters

Ranked set sampling (RSS) method considers the ranking information of sample units and it obtains more representative sample than commonly used simple random sampling (SRS) method. McIntyre [15] is introduced RSS as a sampling method in order to estimate the mean of yields. Takahasi and Wakimoto [16] presented the theoretical background of the RSS method and proved that the RSS give smaller variance than the SRS for the mean estimation when the ranking of the units is perfect. There are several papers which are dealing with the estimation of parameters of a model using RSS method and its modified versions. Lam et al. [17] obtained the estimator for the parameters of two-parameter exponential distribution under RSS. Hassan [18] used maximum likelihood estimation method and Bayesian method for parameter estimation in exponentiated exponential distribution and compared the SRS and RSS methods. Esemen and Gurler [19] estimated the parameters of generalized Rayleigh distribution by using maximum likelihood 
method based on the sample obtained from RSS and its modified versions. For more additional study, see [20-23], and the references therein.

In this paper, we aim to provide the results for the estimation of the parameters for EW distribution by using RSS method. We also illustrate the use of EW distribution as an alternative model for vehicle headway data. In Section 2 and 3, we give some details for the maximum likelihood estimation of the parameters when all parameters are unknown based on SRS and RSS methods, respectively. In Section 4, we present the results of the Monte Carlo simulation study in order to compare the performance of SRS and RSS methods. In Section 5, we give an application for modeling a vehicle headway data using EW distribution to show its convenience. We discuss the results drawn from analysing the data given in the study of Badhrudeen et al. [24]. Finally, in Section 6, we give conclusions.

\section{MAXIMUM LIKELIHOOD ESTIMATION USING SRS}

Consider that $Y_{1}, Y_{2}, \ldots, Y_{m}$ is a random sample of size $m$ from $E W(\alpha, \beta, \lambda)$, where $\alpha, \beta$ and $\lambda$ are unknown. For the maximum likelihood estimation of the parameters, Mudholkar and Srivastava [1] gave the loglikelihood function, $l(\alpha, \beta, \lambda)$, as below

$$
\begin{aligned}
& l(\alpha, \beta, \lambda)=m \log \alpha+m \log \beta+m \beta \log \lambda+(\beta-1) \sum_{s=1}^{m} \log \left(y_{s}\right)-\lambda^{\beta} \sum_{s=1}^{m} y_{s}^{\beta} \\
& \quad+(\alpha-1) \sum_{s=1}^{m} \log \left(1-\exp \left(-\left(\lambda y_{s}\right)^{\beta}\right)\right) .
\end{aligned}
$$

Therefore, maximum likelihood equations for the parameters of EW distribution become,

$$
\begin{aligned}
& \frac{\partial l}{\partial \alpha}=\frac{m}{\alpha}+\sum_{s=1}^{m} \log \left(1-\exp \left(-\left(\lambda y_{s}\right)^{\beta}\right)\right)=0, \\
& \frac{\partial l}{\partial \beta}=\frac{m}{\beta}+m \log \lambda+\sum_{s=1}^{m} \log \left(y_{s}\right)+(\alpha-1) \lambda^{\beta} \sum_{s=1}^{m} \frac{y_{s}^{\beta} \log \left(\lambda y_{s}\right) \exp \left(-\left(\lambda y_{s}\right)^{\beta}\right)}{1-\exp \left(-\left(\lambda y_{s}\right)^{\beta}\right)} \\
& -\lambda^{\beta} \sum_{s=1}^{m} y_{s}^{\beta} \log \left(\lambda y_{s}\right)=0, \\
& \frac{\partial l}{\partial \lambda}=\frac{m \beta}{\lambda}+(\alpha-1) \beta \lambda^{\beta-1} \sum_{s=1}^{m} \frac{\exp \left(-\left(\lambda y_{s}\right)^{\beta}\right) y_{s}^{\beta}}{1-\exp \left(-\left(\lambda y_{s}\right)^{\beta}\right)}-\beta \lambda^{\beta-1} \sum_{s=1}^{m} y_{s}^{\beta}=0 .
\end{aligned}
$$

Since equations given in Equations (5), (6), (7) have nonlinear forms, it is necessary to solve these by using numerical methods to obtain maximum likelihood estimators of the parameters, namely, $\hat{\alpha}_{s r s}, \hat{\beta}_{s r s}, \hat{\lambda}_{s r s}$.

\section{MAXIMUM LIKELIHOOD ESTIMATION USING RSS}

RSS is a useful method for data collection, especially when the procedure of the measurement is time consuming or expensive. When the sampling method is RSS, we should consider the following steps for obtaining a sample of size $k$ (see, [20]):

Step 1: Select randomly $k$ sets with $k$ size of sample units from the target population.

Step 2: Rank the units in each set without measuring the variable of interest. Ranking process can be done by using any inexpensive method, such as using an auxiliary variable, visual inspection or expert judgment etc.

Step 3: Choose from the first set the smallest ranked unit, from the second set the second smallest ranked unit, and so forth until from the last set the largest ranked unit.

The three steps above provides a $k$-sized ranked set sample and this whole procedure is referred as a cycle. The cycle can be repeated $c$ times to obtain a sample of size $m=k c$. 
Suppose $Y_{S(s: k) t}, s=1,2, \ldots, k, t=1,2, \ldots, c$ is a ranked set sample of size $m=k c$ drawn from EW distribution where $k$ and $c$ are the set size and the cycle size, respectively. We represent $Y_{s(s: k) t}$ by $X_{s t}$, which is the $s$ th order statistic, in order to simplify the following formulations. The pdf of $X_{s t}$ is

$h_{s}\left(x_{s t}\right)=\frac{k !}{(s-1) !(k-s) !} g\left(x_{s t}\right)\left[G\left(x_{s t}\right)\right]^{s-1}\left[1-G\left(x_{s t}\right)\right]^{k-s}$,

where $g\left(x_{s t}\right)$ denotes the pdf and $G\left(x_{s t}\right)$ denotes the cdf. The likelihood function for EW distribution using RSS can be written as

$$
\begin{aligned}
L^{*}(\alpha, \beta, \lambda)= & \prod_{t=1}^{c} \prod_{s=1}^{k} h_{s}\left(x_{s t} ; \alpha, \beta, \lambda\right) \\
= & A^{k c} \alpha^{k c} \beta^{k c} \lambda^{k c \beta} \prod_{t=1}^{c} \prod_{s=1}^{k} x_{s t}^{\beta-1} \exp \left(-\left(\lambda x_{s t}\right)^{\beta}\right)\left(1-\exp \left(-\left(\lambda x_{s t}\right)^{\beta}\right)\right)^{\alpha s-1} \\
& \times\left(1-\left(1-\exp \left(-\left(\lambda x_{s t}\right)^{\beta}\right)\right)^{\alpha}\right)^{k-s}
\end{aligned}
$$

where $A=\frac{k !}{(k-s) !(s-1) !}$. Then, the log-likelihood function is

$$
\begin{aligned}
l^{*}(\alpha, \beta, \lambda)= & k c \log A+k c \log \alpha+k c \log \beta+k c \beta \log \lambda+(\beta-1) \sum_{t=1}^{c} \sum_{s=1}^{k} \log \left(x_{s t}\right) \\
& -\lambda^{\beta} \sum_{t=1}^{c} \sum_{s=1}^{k} x_{s t}^{\beta}+\sum_{t=1}^{c} \sum_{s=1}^{k}(\alpha s-1) \log \left(1-\exp \left(-\left(\lambda x_{s t}\right)^{\beta}\right)\right) \\
& +\sum_{t=1}^{c} \sum_{s=1}^{k}(k-s) \log \left(1-\left(1-\exp \left(-\left(\lambda x_{s t}\right)^{\beta}\right)\right)^{\alpha}\right) .
\end{aligned}
$$

Maximum likelihood equations for each parameter are given in the following:

$$
\begin{aligned}
\frac{\partial l^{*}}{\partial \alpha}= & \frac{k c}{\alpha}+\sum_{t=1}^{c} \sum_{s=1}^{k} s \log \left(1-\exp \left(-\left(\lambda x_{s t}\right)^{\beta}\right)\right) \\
& -\sum_{t=1}^{c} \sum_{s=1}^{k}(k-s) \frac{\left(1-\exp \left(-\left(\lambda x_{s t}\right)^{\beta}\right)\right)^{\alpha} \log \left(1-\exp \left(-\left(\lambda x_{s t}\right)^{\beta}\right)\right)}{1-\left(1-\exp \left(-\left(\lambda x_{s t}\right)^{\beta}\right)\right)^{\alpha}}=0 \\
\frac{\partial l^{*}}{\partial \beta}= & \frac{k c}{\beta}+k c \log \lambda+\sum_{t=1}^{c} \sum_{s=1}^{k} \log \left(x_{s t}\right)-\lambda^{\beta} \log \lambda \sum_{t=1}^{c} \sum_{s=1}^{k} x_{s t}^{\beta}-\lambda^{\beta} \sum_{s=1}^{k} x_{s t}^{\beta} \log \left(x_{s t}\right) \\
& -\sum_{t=1}^{c} \sum_{s=1}^{k}(k-s) \frac{\alpha \log \left(\lambda x_{s t}\right)\left(\lambda x_{s t}\right)^{\beta}\left(1-\exp \left(-\left(\lambda x_{s t}\right)^{\beta}\right)\right)^{\alpha-1} \exp \left(-\left(\lambda x_{s t}\right)^{\beta}\right)}{1-\left(1-\exp \left(-\left(\lambda x_{s t}\right)^{\beta}\right)\right)^{\alpha}} \\
& +\sum_{t=1}^{c} \sum_{s=1}^{k}(\alpha s-1) \frac{\left(\lambda x_{s t}\right)^{\beta} \exp \left(-\left(\lambda x_{s t}\right)^{\beta}\right) \log \left(\lambda x_{s t}\right)}{1-\exp \left(-\left(\lambda x_{s t}\right)^{\beta}\right)}=0 \\
\frac{\partial l^{*}}{\partial \lambda}= & \frac{k c \beta}{\lambda}-\beta \lambda^{\beta-1} \sum_{t=1}^{c} \sum_{s=1}^{k} x_{s t}^{\beta}+\sum_{t=1}^{c} \sum_{s=1}^{k}(\alpha s-1) \frac{\beta x_{s t}\left(\lambda x_{s t}\right)^{\beta-1} \exp \left(-\left(\lambda x_{s t}\right)^{\beta}\right)}{1-\exp \left(-\left(\lambda x_{s t}\right)^{\beta}\right)} \\
& -\sum_{t=1}^{c} \sum_{s=1}^{k}(k-s) \frac{\alpha \beta x_{s t}\left(\lambda x_{s t}\right)^{\beta-1} \exp \left(-\left(\lambda x_{s t}\right)^{\beta}\right)\left(1-\exp \left(-\left(\lambda x_{s t}\right)^{\beta}\right)\right)^{\alpha-1}}{1-\left(1-\exp \left(-\left(\lambda x_{s t}\right)^{\beta}\right)\right)^{\alpha}}=0 .
\end{aligned}
$$

Since the maximum likelihood equations obtained for estimation of parameters are in nonlinear forms, they should be solved by numerical methods to obtain maximum likelihood estimates namely, $\hat{\alpha}_{r s s}, \hat{\beta}_{r s s}, \hat{\lambda}_{r s s}$. 


\section{NUMERICAL RESULTS}

In this section, we conduct a Monte Carlo simulation for numerical comparison of the SRS and RSS for estimating the unknown parameters $(\alpha, \beta$, and $\lambda)$ of EW distribution using the maximum likelihood method. In numerical analysis, a quasi-Newton type algorithm is used to approximate solutions of the maximum likelihood equations. The study is designed using R-software with $N=10,000$ repetitions for different values of sample size $(m)$. In addition, different values for $\alpha, \beta$, and $\lambda$ parameters are considered to obtain different shapes of EW distribution. The numerical results of bias and mean squared error (MSE) are obtained by the following formulations, respectively,

$$
\begin{gathered}
\operatorname{bias}(\hat{\theta})=\frac{1}{N} \sum_{s=1}^{N}\left(\hat{\theta}_{s}-\theta\right), \\
\operatorname{MSE}(\hat{\theta})=\frac{1}{N} \sum_{s=1}^{N}\left(\hat{\theta}_{S}-\theta\right)^{2},
\end{gathered}
$$

where $\hat{\theta}$ is the estimator of $\theta$ parameter and $\hat{\theta}_{S}$ represents the estimation of parameter in $s^{\text {th }}$ repetition for $s=1, \ldots, N$.

Tables 1 and 2 show the estimated MSE and bias values of the parameters, respectively. We numerically observe that MSE values based on RSS are smaller than the values based on SRS for all cases. One can conclude that the MSE values are high for small sample sizes for the parameter $\lambda$ in the case of $(0.5 ; 1.5 ; 2.5)$. In addition, MSE values based on RSS method decrease as the set size increases for all parameters. Moreover, the bias values in Table 2 show that both sampling methods give biased estimation values with ML method.

\begin{tabular}{|c|c|c|c|c|c|c|c|c|}
\hline$(\alpha ; \beta ; \lambda)$ & $m$ & $\hat{\alpha}_{s r s}$ & $\hat{\beta}_{\text {srs }}$ & $\hat{\lambda}_{s r s}$ & $(k ; c)$ & $\hat{\alpha}_{r s s}$ & $\hat{\beta}_{r S S}$ & $\hat{\lambda}_{r s s}$ \\
\hline \multirow[t]{12}{*}{$(2 ; 0.8 ; 2)$} & \multirow[t]{3}{*}{12} & \multirow[t]{3}{*}{1.8605} & \multirow[t]{3}{*}{0.6490} & \multirow[t]{3}{*}{2.2361} & $(3 ; 4)$ & 1.5435 & 0.5288 & 1.6833 \\
\hline & & & & & $(4 ; 3)$ & 1.5065 & 0.5320 & 1.6814 \\
\hline & & & & & $(6 ; 2)$ & 1.3241 & 0.4842 & 1.3158 \\
\hline & \multirow[t]{3}{*}{24} & \multirow[t]{3}{*}{1.7822} & \multirow[t]{3}{*}{0.3867} & \multirow[t]{3}{*}{2.2826} & $(3 ; 8)$ & 1.4777 & 0.3313 & 1.7156 \\
\hline & & & & & $(4 ; 6)$ & 1.3970 & 0.3276 & 1.5903 \\
\hline & & & & & $(6 ; 4)$ & 1.1829 & 0.3042 & 1.2787 \\
\hline & \multirow[t]{3}{*}{48} & \multirow[t]{3}{*}{1.5893} & \multirow[t]{3}{*}{0.1847} & \multirow[t]{3}{*}{2.2706} & $(3 ; 16)$ & 1.3428 & 0.1505 & 1.7203 \\
\hline & & & & & $(4 ; 12)$ & 1.2170 & 0.1445 & 1.5080 \\
\hline & & & & & $(6 ; 8)$ & 1.0094 & 0.1279 & 1.2038 \\
\hline & \multirow[t]{3}{*}{96} & \multirow[t]{3}{*}{1.2852} & \multirow[t]{3}{*}{0.0667} & \multirow[t]{3}{*}{1.9634} & $(3 ; 32)$ & 1.0330 & 0.0565 & 1.4225 \\
\hline & & & & & $(4 ; 24)$ & 0.9892 & 0.0513 & 1.3432 \\
\hline & & & & & $(6 ; 16)$ & 0.7666 & 0.0432 & 0.9909 \\
\hline \multirow[t]{12}{*}{$(2 ; 1.5 ; 2)$} & \multirow[t]{3}{*}{12} & \multirow[t]{3}{*}{3.8382} & \multirow[t]{3}{*}{1.3380} & \multirow[t]{3}{*}{1.0787} & $(3 ; 4)$ & 3.0376 & 0.7630 & 0.8230 \\
\hline & & & & & $(4 ; 3)$ & 2.6299 & 0.8299 & 0.7334 \\
\hline & & & & & $(6 ; 2)$ & 1.8949 & 1.1963 & 0.5511 \\
\hline & \multirow[t]{3}{*}{24} & \multirow[t]{3}{*}{3.4557} & \multirow[t]{3}{*}{0.8576} & \multirow[t]{3}{*}{1.0135} & $(3 ; 8)$ & 2.7100 & 0.5032 & 0.7645 \\
\hline & & & & & $(4 ; 6)$ & 2.3642 & 0.5343 & 0.6478 \\
\hline & & & & & $(6 ; 4)$ & 1.8448 & 0.7671 & 0.5465 \\
\hline & \multirow[t]{3}{*}{48} & \multirow[t]{3}{*}{3.0878} & \multirow[t]{3}{*}{0.5005} & \multirow[t]{3}{*}{0.8976} & $(3 ; 16)$ & 2.2815 & 0.3374 & 0.6500 \\
\hline & & & & & $(4 ; 12)$ & 2.0997 & 0.3257 & 0.6062 \\
\hline & & & & & $(6 ; 8)$ & 1.5208 & 0.3840 & 0.4337 \\
\hline & \multirow[t]{3}{*}{96} & \multirow[t]{3}{*}{2.2837} & 0.2594 & 0.6784 & $(3 ; 32)$ & 1.7379 & 0.1885 & 0.5000 \\
\hline & & & & & $(4 ; 24)$ & 1.5303 & 0.1727 & 0.4401 \\
\hline & & & & & $(6 ; 16)$ & 1.1161 & 0.1688 & 0.3259 \\
\hline$(0.5 ; 1.5 ; 2.5)$ & 12 & 0.7459 & 0.6505 & 10.1066 & $(3 ; 4)$ & 0.5544 & 0.6325 & 7.6216 \\
\hline
\end{tabular}

Table 1. The estimated MSE values for parameters of the EW distribution based on SRS and RSS 


\begin{tabular}{|c|c|c|c|c|c|c|c|c|}
\hline & & & & & $(4 ; 3)$ & 0.4868 & 0.5849 & 6.6253 \\
\hline & & & & & $(6 ; 2)$ & 0.4152 & 0.5397 & 5.3953 \\
\hline & \multirow[t]{3}{*}{24} & \multirow[t]{3}{*}{0.4620} & \multirow[t]{3}{*}{0.4318} & \multirow[t]{3}{*}{7.6939} & $(3 ; 8)$ & 0.3330 & 0.4302 & 4.7245 \\
\hline & & & & & $(4 ; 6)$ & 0.3081 & 0.4287 & 4.3945 \\
\hline & & & & & $(6 ; 4)$ & 0.2475 & 0.4056 & 3.4146 \\
\hline & \multirow[t]{3}{*}{48} & \multirow[t]{3}{*}{0.2184} & \multirow[t]{3}{*}{0.3186} & \multirow[t]{3}{*}{3.6440} & $(3 ; 16)$ & 0.1668 & 0.3014 & 2.4107 \\
\hline & & & & & $(4 ; 12)$ & 0.1504 & 0.2907 & 2.1035 \\
\hline & & & & & $(6 ; 8)$ & 0.1156 & 0.2819 & 1.4939 \\
\hline & \multirow[t]{3}{*}{96} & \multirow[t]{3}{*}{0.0833} & \multirow[t]{3}{*}{0.1859} & \multirow[t]{3}{*}{1.2315} & $(3 ; 32)$ & 0.0636 & 0.1767 & 0.8009 \\
\hline & & & & & $(4 ; 24)$ & 0.0531 & 0.1628 & 0.6296 \\
\hline & & & & & $(6 ; 16)$ & 0.0473 & 0.1530 & 0.5415 \\
\hline \multirow[t]{12}{*}{$(0.8 ; 0.8 ; 1)$} & \multirow[t]{3}{*}{12} & \multirow[t]{3}{*}{0.8692} & \multirow[t]{3}{*}{0.2417} & \multirow[t]{3}{*}{4.5121} & $(3 ; 4)$ & 0.5877 & 0.1925 & 2.8218 \\
\hline & & & & & $(4 ; 3)$ & 0.5827 & 0.1836 & 2.4713 \\
\hline & & & & & $(6 ; 2)$ & 0.5088 & 0.1535 & 1.9837 \\
\hline & \multirow[t]{3}{*}{24} & \multirow{3}{*}{0.6621} & \multirow[t]{3}{*}{0.1494} & \multirow[t]{3}{*}{3.6248} & $(3 ; 8)$ & 0.4840 & 0.1300 & 2.3875 \\
\hline & & & & & $(4 ; 6)$ & 0.4226 & 0.1291 & 1.8962 \\
\hline & & & & & $(6 ; 4)$ & 0.3530 & 0.1143 & 1.4309 \\
\hline & \multirow[t]{3}{*}{48} & \multirow[t]{3}{*}{0.4276} & \multirow[t]{3}{*}{0.0940} & \multirow[t]{3}{*}{2.4840} & $(3 ; 16)$ & 0.3334 & 0.0915 & 1.5563 \\
\hline & & & & & $(4 ; 12)$ & 0.2988 & 0.0878 & 1.2995 \\
\hline & & & & & $(6 ; 8)$ & 0.2497 & 0.0795 & 0.9663 \\
\hline & \multirow[t]{3}{*}{96} & \multirow[t]{3}{*}{0.2360} & \multirow[t]{3}{*}{0.0578} & \multirow[t]{3}{*}{1.2053} & $(3 ; 32)$ & 0.1917 & 0.0541 & 0.7589 \\
\hline & & & & & $(4 ; 24)$ & 0.1651 & 0.0530 & 0.5904 \\
\hline & & & & & $(6 ; 16)$ & 0.1457 & 0.0474 & 0.4772 \\
\hline
\end{tabular}

Table 2. The estimated bias values for parameters of the EW distribution based on SRS and RSS

\begin{tabular}{|c|c|c|c|c|c|c|c|c|}
\hline$(\alpha ; \beta ; \lambda)$ & $m$ & $\hat{\alpha}_{s r s}$ & $\hat{\beta}_{\text {srs }}$ & $\hat{\lambda}_{s r s}$ & $(k ; c)$ & $\hat{\alpha}_{r s s}$ & $\hat{\beta}_{r S S}$ & $\hat{\lambda}_{r s s}$ \\
\hline \multirow[t]{12}{*}{$(2 ; 0.8 ; 2)$} & \multirow[t]{3}{*}{12} & \multirow[t]{3}{*}{-0.1975} & \multirow[t]{3}{*}{0.4590} & \multirow[t]{3}{*}{-0.0689} & $(3 ; 4)$ & -0.2618 & 0.4150 & -0.1381 \\
\hline & & & & & $(4 ; 3)$ & -0.2911 & 0.4176 & -0.1551 \\
\hline & & & & & $(6 ; 2)$ & -0.3306 & 0.3957 & -0.2241 \\
\hline & \multirow[t]{3}{*}{24} & \multirow[t]{3}{*}{-0.1009} & \multirow[t]{3}{*}{0.3245} & \multirow[t]{3}{*}{0.0501} & $(3 ; 8)$ & -0.1602 & 0.2984 & -0.0332 \\
\hline & & & & & $(4 ; 6)$ & -0.1816 & 0.2968 & -0.0577 \\
\hline & & & & & $(6 ; 4)$ & -0.2554 & 0.2882 & -0.1412 \\
\hline & \multirow[t]{3}{*}{48} & \multirow[t]{3}{*}{0.0668} & \multirow[t]{3}{*}{0.1781} & \multirow[t]{3}{*}{0.2265} & $(3 ; 16)$ & 0.0388 & 0.1563 & 0.1627 \\
\hline & & & & & $(4 ; 12)$ & 0.0294 & 0.1480 & 0.1438 \\
\hline & & & & & $(6 ; 8)$ & -0.0466 & 0.1471 & 0.0528 \\
\hline & \multirow[t]{3}{*}{96} & \multirow[t]{3}{*}{0.2158} & \multirow[t]{3}{*}{0.0656} & \multirow[t]{3}{*}{0.3578} & $(3 ; 32)$ & 0.1911 & 0.0532 & 0.3021 \\
\hline & & & & & $(4 ; 24)$ & 0.1837 & 0.0496 & 0.2870 \\
\hline & & & & & $(6 ; 16)$ & 0.1045 & 0.0525 & 0.1866 \\
\hline \multirow[t]{12}{*}{$(2 ; 1.5 ; 2)$} & \multirow[t]{3}{*}{12} & \multirow[t]{3}{*}{0.3510} & \multirow[t]{3}{*}{0.5520} & \multirow[t]{3}{*}{0.1531} & $(3 ; 4)$ & 0.3691 & 0.3625 & 0.1494 \\
\hline & & & & & $(4 ; 3)$ & 0.2898 & 0.3786 & 0.1231 \\
\hline & & & & & $(6 ; 2)$ & 0.0494 & 0.5564 & 0.0491 \\
\hline & \multirow[t]{3}{*}{24} & \multirow[t]{3}{*}{0.3426} & \multirow[t]{3}{*}{0.3962} & \multirow[t]{3}{*}{0.1575} & $(3 ; 8)$ & 0.3348 & 0.2719 & 0.1475 \\
\hline & & & & & $(4 ; 6)$ & 0.2662 & 0.2793 & 0.1143 \\
\hline & & & & & $(6 ; 4)$ & 0.0427 & 0.3958 & 0.0063 \\
\hline & \multirow[t]{3}{*}{48} & \multirow[t]{3}{*}{0.3814} & \multirow[t]{3}{*}{0.2450} & \multirow[t]{3}{*}{0.1866} & $(3 ; 16)$ & 0.3193 & 0.1834 & 0.1509 \\
\hline & & & & & $(4 ; 12)$ & 0.3121 & 0.1655 & 0.1555 \\
\hline & & & & & $(6 ; 8)$ & 0.1296 & 0.2241 & 0.0537 \\
\hline & \multirow[t]{3}{*}{96} & \multirow[t]{3}{*}{0.3781} & 0.1191 & 0.1963 & $(3 ; 32)$ & 0.3215 & 0.0905 & 0.1608 \\
\hline & & & & & $(4 ; 24)$ & 0.2816 & 0.0865 & 0.1417 \\
\hline & & & & & $(6 ; 16)$ & 0.1771 & 0.0981 & 0.0877 \\
\hline
\end{tabular}




\begin{tabular}{|c|c|c|c|c|c|c|c|c|}
\hline \multirow{12}{*}{$(0.5 ; 1.5 ; 2.5)$} & \multirow[t]{3}{*}{12} & \multirow[t]{3}{*}{-0.4064} & \multirow[t]{3}{*}{-0.0916} & \multirow{3}{*}{-1.6464} & $(3 ; 4)$ & -0.3356 & -0.1072 & -1.3677 \\
\hline & & & & & $(4 ; 3)$ & -0.3048 & -0.0977 & -1.2323 \\
\hline & & & & & $(6 ; 2)$ & -0.2746 & -0.0891 & -1.0904 \\
\hline & \multirow[t]{3}{*}{24} & \multirow[t]{3}{*}{-0.3028} & \multirow[t]{3}{*}{-0.0221} & \multirow[t]{3}{*}{-1.2932} & $(3 ; 8)$ & -0.2393 & -0.0523 & -0.9724 \\
\hline & & & & & $(4 ; 6)$ & -0.2217 & -0.0681 & -0.9101 \\
\hline & & & & & $(6 ; 4)$ & -0.1898 & -0.0673 & -0.7670 \\
\hline & \multirow[t]{3}{*}{48} & \multirow[t]{3}{*}{-0.1757} & \multirow[t]{3}{*}{-0.0363} & \multirow[t]{3}{*}{-0.7556} & $(3 ; 16)$ & -0.1343 & -0.0610 & -0.5627 \\
\hline & & & & & $(4 ; 12)$ & -0.1271 & -0.0594 & -0.5230 \\
\hline & & & & & $(6 ; 8)$ & -0.0985 & -0.0778 & -0.4074 \\
\hline & \multirow[t]{3}{*}{96} & \multirow[t]{3}{*}{-0.0850} & \multirow[t]{3}{*}{-0.0358} & \multirow[t]{3}{*}{-0.3595} & $(3 ; 32)$ & -0.0632 & -0.0501 & -0.2622 \\
\hline & & & & & $(4 ; 24)$ & -0.0529 & -0.0520 & -0.2157 \\
\hline & & & & & $(6 ; 16)$ & -0.0452 & -0.0566 & -0.1879 \\
\hline \multirow[t]{12}{*}{$(0.8 ; 0.8 ; 1)$} & \multirow[t]{3}{*}{12} & \multirow[t]{3}{*}{0.3502} & \multirow[t]{3}{*}{0.1609} & \multirow[t]{3}{*}{0.8925} & $(3 ; 4)$ & 0.2316 & 0.1469 & 0.6418 \\
\hline & & & & & $(4 ; 3)$ & 0.2542 & 0.1273 & 0.6379 \\
\hline & & & & & $(6 ; 2)$ & 0.2339 & 0.1074 & 0.5723 \\
\hline & \multirow[t]{3}{*}{24} & \multirow[t]{3}{*}{0.2993} & \multirow[t]{3}{*}{0.0874} & \multirow[t]{3}{*}{0.7921} & $(3 ; 8)$ & 0.2293 & 0.0847 & 0.5891 \\
\hline & & & & & $(4 ; 6)$ & 0.2046 & 0.0853 & 0.5291 \\
\hline & & & & & $(6 ; 4)$ & 0.1698 & 0.0824 & 0.4373 \\
\hline & \multirow[t]{3}{*}{48} & \multirow[t]{3}{*}{0.2224} & \multirow[t]{3}{*}{0.0486} & \multirow[t]{3}{*}{0.6076} & $(3 ; 16)$ & 0.1813 & 0.0522 & 0.4632 \\
\hline & & & & & $(4 ; 12)$ & 0.1565 & 0.0569 & 0.4054 \\
\hline & & & & & $(6 ; 8)$ & 0.1296 & 0.0570 & 0.3325 \\
\hline & \multirow[t]{3}{*}{96} & \multirow[t]{3}{*}{0.1357} & \multirow[t]{3}{*}{0.0325} & 0.3622 & $(3 ; 32)$ & 0.1093 & 0.0348 & 0.2744 \\
\hline & & & & & $(4 ; 24)$ & 0.0988 & 0.0348 & 0.2439 \\
\hline & & & & & $(6 ; 16)$ & 0.0892 & 0.0311 & 0.2153 \\
\hline
\end{tabular}

\section{MODELING OF VEHICLE HEADWAY DATA USING EW DISTRIBUTION}

Modeling of the headway data is essential for traffic signal optimization and flow modeling in traffic engineering. Vehicle headway is defined as the time interval between successive arrival of vehicles in a lane and is a key topic for many traffic flow optimization studies and vehicle simulation problems. During the last two decades, statistical modeling of vehicle headway data has received considerable attention and various distributions are available where it can be used for different traffic conditions. Some of the statistical distributions found suitable for modelling vehicle headway are inverse Weibull [25], shifted lognormal [26], gamma [26,27], negative exponential [27], lognormal [28-30], log-logistic [29,31], and generalized extreme value [32]. Recently, Li and Chen [33] presented a comprehensive review on the vehicle headway modeling and provide the genealogical tree of headway models used in past studies.

Badhrudeen et al. [24] proposed to use of the Weibull distribution as the best model fitted for vehicle headway data in India. In their study, the headway observations are collected from an automated sensor located on an urban road consisting of six lanes and analysed separately based on the leader-follower pairs and also for the specific time of a day. They found that the best model for the headway data between the hours 07:30 am and 10:45 am was the Weibull distribution and they estimated the shape and the scale parameters as 1.9718 and 2.6372, respectively. In this section, we generate a data set from the results of the study of Badhrudeen et al. [24]. The generated data set consists of 1000 observations for the vehicle headway between the hours 07:30 and 10:45. Table 3 gives the summary statistics of the data set. For the estimation procedure of the parameters for EW distribution, we used a quasi-Newton type algorithm in Rsoftware to maximize the likelihood function and obtain that the maximum likelihood estimates as $\hat{\alpha}=$ $1.3475, \hat{\beta}=1.7686$, and $\hat{\lambda}=0.4233$. We found that the EW distribution provides an acceptable fit for the generated headway data according to the Anderson-Darling goodness of fit test, A-D=0.4195, $p-$ value $=0.8293$. 
Table 3. Descriptive statistics of the generated data set

\begin{tabular}{|l|l|l|l|l|l|}
\hline $\mathrm{N}$ & Min & Max & Mean & Median & $\begin{array}{l}\text { Standard } \\
\text { deviation }\end{array}$ \\
\hline 1000 & 0.2111 & 6.8711 & 2.3959 & 2.2470 & 1.2161 \\
\hline
\end{tabular}

In order to estimate the parameters of EW distribution, we select two sets of sample of size $m=40$ from the generated headway data by SRS and RSS methods. For the RSS method, we select the set size and the cycle size as $k=5$ and $c=8$ and the sample is drawn with replacement. The maximum likelihood estimates of the parameters of EW distribution based on SRS and RSS are given in Table 4. KolmogorovSmirnov test indicates that both the samples by SRS and RSS methods follow EW distribution with the estimated parameters, $\mathrm{D}_{\mathrm{SRS}}=0.0899, p-$ value $=0.8740 ; \mathrm{D}_{\mathrm{RSS}}=0.0806, p-$ value $=0.9389$, respectively. Figure 3 shows the histogram of the generated headway data and the shapes of EW models for two different sampling methods with parameter values given in Table 4.

Table 4. Estimated parameter values of EW distribution using SRS and RSS methods

\begin{tabular}{|l|l|l|l|}
\hline \multirow{2}{*}{} & \multicolumn{1}{|c|}{$\hat{\alpha}$} & $\hat{\beta}$ & \\
$\hat{\lambda}$ \\
\hline SRS & & & $\hat{\lambda}$ \\
\hline RSS & 0.6135 & 2.3532 & 0.3103 \\
\hline
\end{tabular}

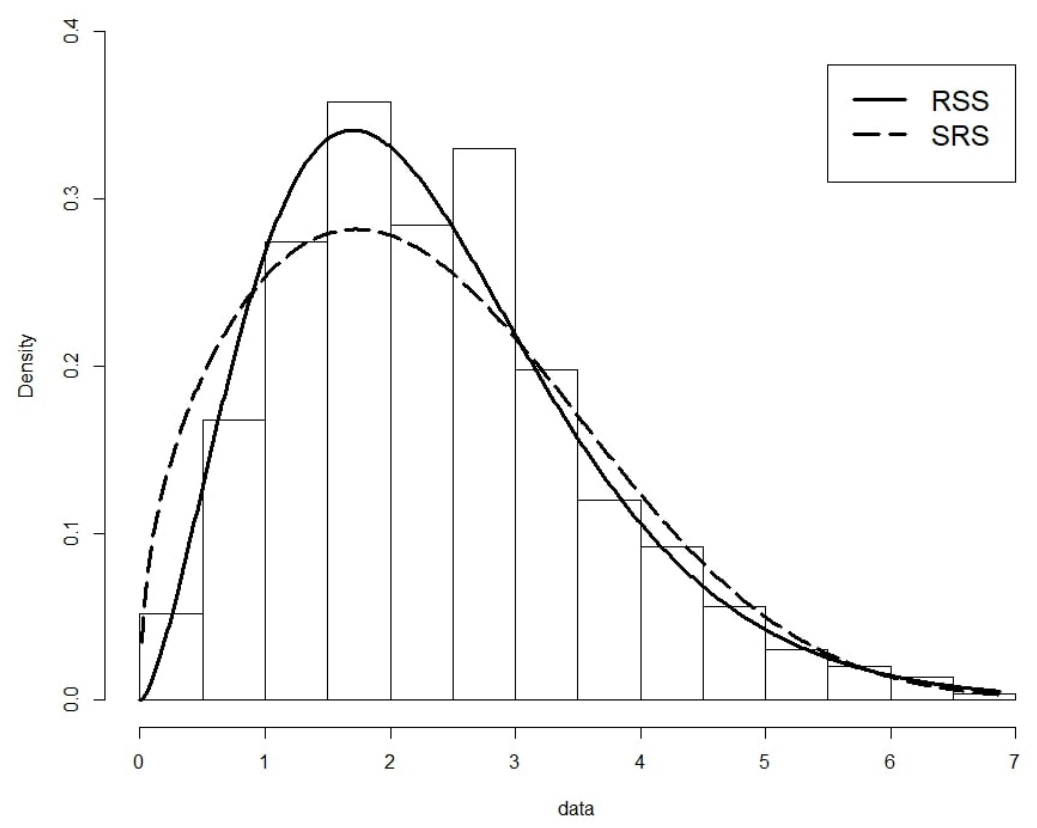

Figure 3. Histogram of the generated data and the pdfs of the fitted models using SRS and RSS

\section{CONCLUSION}

In this study, maximum likelihood equations for parameters of EW distribution are obtained based on RSS when all parameters are unknown. The Monte Carlo simulation study is conducted in R-software in order to compare the performances of the RSS and SRS methods on the parameter estimation of EW distribution. The results support that RSS gives more efficient result than SRS method based on their MSE values for all cases of sample and set sizes. Also, an application based on a simulation from real data for vehicle headway is presented to show the flexibility of EW distribution. It is seen that EW distribution may be used as an alternative model for the vehicle time headway data in transportation studies. 


\section{ACKNOWLEDGEMENT}

We are grateful to the editor and anonymous referees for their valuable comments and recommendations. The first and the third authors would like to thank to the Scientific and Technological Research Council of Turkey (TUBITAK) for funding their studies through 2211/A Fellowship programme.

\section{CONFLICTS OF INTEREST}

No conflict of interest was declared by the authors.

\section{REFERENCES}

[1] Mudholkar, G.S., Srivastava, D. K., "Exponentiated Weibull family for analyzing bathtub failurerate data", IEEE Transactions on Reliability, 42(2): 299-302, (1993).

[2] Pal, M., Ali, M.M., Woo, J., "Exponentiated Weibull distribution", Statistica, 66(2): 13-147, (2006).

[3] Shittu, O.I., Adepoju, K.A., "On the exponentiated Weibull distribution for modeling wind speed in south western Nigeria", Journal of Modern Applied Statistical Methods ,13(1): 431-445, (2014).

[4] Elshahhat, A., "Parameters estimation for the exponentiated Weibull distribution based on generalized progressive hybrid censoring schemes", American Journal of Applied Mathematics and Statistics, 5(2): 33-48, (2017).

[5] Ghnimi, S., Gasmi, S., "Parameter estimations for some modifications of the Weibull distribution.", Open Journal of Statistics ,4(8): 597-610, (2014).

[6] Mudholkar, G.S., Srivastava, D.K., Freimer, M., "The exponentiated Weibull family: A reanalysis of the bus-motor-failure data", Technometrics, 37(4): 436-445, (1995).

[7] Achcar, J.A., Rodriguez, G.O., Rodrigues, E.R., "Estimating the number of ozone peaks in Mexico City using a non-homogeneous Poisson model and a Metropolis-Hastings algorithm”, International Journal of Pure and Applied Mathematics, 53(1): 1-20, (2009).

[8] Barrios, R., Dios, F., "Exponentiated Weibull model for the irradiance probability density function of a laser beam propagating through atmospheric turbulence", Optics \& Laser Technology, 45: 1320, (2013).

[9] Cancho, V.G., Bolfarine, H., "Modeling the presence of immunes by using the exponentiatedWeibull model", Journal of Applied Statistics, 28(6): 659-671, (2001).

[10] Jiang, R., "Discrete competing risk model with application to modeling bus-motor failure data", Reliability Engineering \& System Safety, 95(9): 981-988 (2010).

[11] Mudholkar, G.S., Hutson, A.D., "The exponentiated Weibull family: Some properties and a flood data application", Communications in Statistics-Theory and Methods, 25(12): 3059-3083, (1996).

[12] Nassar, M.M., Eissa, F.H., "On the exponentiated Weibull distribution", Communications in Statistics-Theory and Methods, 32(7): 1317-1336, (2003).

[13] Almalki, S.J., Nadarajah, S., "Modifications of the Weibull distribution: A review", Reliability Engineering \& System Safety, 124: 32-55, (2014).

[14] Nadarajah, S., Cordeiro, G.M., Ortega, E.M., "The exponentiated Weibull distribution: A survey", Statistical Papers, 54 (3): 839-877, (2013). 
[15] McIntyre, G.A., "A method for unbiased selective sampling, using ranked sets", Australian Journal of Agricultural Research, 3(4): 385-390, (1952).

[16] Takahasi, K., Wakimoto, K.,"On unbiased estimates of the population mean based on the sample stratified by means of ordering", Annals of the Institute of Statistical Mathematics, 20(1): 1-31, (1968).

[17] Lam, K., Sinha, B.K., Wu, Z., "Estimation of parameters in a two-parameter exponential distribution using ranked set sample", Annals of the Institute of Statistical Mathematics, 46(4): 723-736, (1994).

[18] Hassan, A.S., "Maximum likelihood and Bayes estimators of the unknown parameters for exponentiated exponential distribution using ranked set sampling", International Journal of Engineering Research and Applications, 3: 720-725, (2013).

[19] Esemen, M., Gürler, S., "Parameter estimation of generalized Rayleigh distribution based on ranked set sample", Journal of Statistical Computation and Simulation, 88(4): 615-628, (2018).

[20] Al-Omari, A.I., Bouza, C.N., "Review of ranked set sampling: modifications and applications", Investigación Operacional, 35(3): 215-241, (2014).

[21] Barabesi, L., El-Sharaawi, A., "The efficiency of ranked set sampling for parameter estimation", Statistics \& Probability Letters, 53(2): 189-199, (2001).

[22] Qian, W., Chen, W., He, X., "Parameter estimation for the Pareto distribution based on ranked set sampling", Statistical Papers, 1-23, (2019).

[23] Shaibu, A.B., Muttlak, H.A., "Estimating the parameters of the normal, exponential and gamma distributions using median and extreme ranked set samples", Statistica, 64(1): 75-98, (2004).

[24] Badhrudeen, M., Ramesh, V., Vanajakshi, L., "Headway analysis using automated sensor data under Indian traffic conditions", Transportation Research Procedia, 17: 331-339, (2016).

[25] Riccardo, R., Massimiliano, G., "An empirical analysis of vehicle time headways on rural two-lane two-way roads", Procedia-Social and Behavioral Sciences, 54: 865-874, (2012).

[26] Abtahi, S.M., Tamannaei, M., Haghshenash, H., "Analysis and modeling time headway distributions under heavy traffic flow conditions in the urban highways: case of Isfahan", Transport, 26(4): 375-382, (2011).

[27] Al-Ghamdi, A.S., "Analysis of time headways on urban roads: Case study from Riyadh", Journal of Transportation Engineering, 127(4): 289-294, (2001).

[28] Greenberg, L., "The log normal distribution of headways”, Australian Road Research, 2(7): 14-18, (1966).

[29] Yin, S., Li, Z., Zhang, Y., Yao, D., Su, Y., Li L., "Headway distribution modeling with regard to traffic status", In 2009 IEEE Intelligent Vehicles Symposium, 1057-1062, (2009).

[30] Dey, P.P., Chandra, S., "Desired time gap and time headway in steady-state car-following on twolane roads", Journal of Transportation Engineering, 135(10): 687-693, (2009).

[31] Jang, J., "Analysis of time headway distribution on suburban arterial", KSCE Journal of Civil Engineering, 16(4): 644-649, (2012). 
[32] Panichpapiboon, S., "Time-headway distributions on an expressway: case of Bangkok", Journal of Transportation Engineering, 141(1): 1-8, (2014).

[33] Li, L., Chen, X. M., "Vehicle headway modeling and its inferences in macroscopic/microscopic traffic flow theory: A survey", Transportation Research Part C: Emerging Technologies ,76: 170188, (2017). 